\title{
Time trends in opioid prescribing among Ontario long-term care residents: a repeated cross-sectional study
}

\author{
Andrea Iaboni MD DPhil, Michael A. Campitelli MPH, Susan E. Bronskill PhD, Christina Diong MSc, \\ Matthew Kumar MSc, Laura C. Maclagan MSc, Tara Gomes PhD, Mina Tadrous PharmD PhD, \\ Colleen J. Maxwell PhD
}

\section{Abstract}

Background: Opioids are an important pain therapy, but their use may be associated with adverse events in frail and cognitively impaired long-term care residents. The objective of this study was to investigate trends in opioid prescribing among Ontario long-term care residents over time, given the paucity of data for this setting.

Methods: We used linked clinical and health administrative databases to conduct a population-based, repeated cross-sectional study of opioid use among Ontario long-term care residents between Apr. 1, 2009, and Mar. 31, 2017. We identified prevalent opioid use by drug type, dosage and coprescription with benzodiazepines, and within certain vulnerable subgroups. We used log-binomial regression to quantify the percent change between 2009/10 and 2016/17.

Results: Among an average of 76147 long-term care residents per year, the prevalence of opioid use increased from $15.8 \%$ in $2009 / 10$ to $19.6 \%$ in $2016 / 17$ ( $p<0.001$ ). Over the study period, the use of hydromorphone increased by $233.2 \%$, whereas the use of all other opioid agents decreased. The use of high-dose opioids (> $90 \mathrm{mg}$ of morphine equivalents) and the coprescription of opioids with benzodiazepines decreased significantly, by $17.7 \%(p<0.001)$ and $23.8 \%(p<0.001)$, respectively. Increases in opioid prevalence were more notable among frail residents $(37.6 \%$ v. $18.8 \%$ among nonfrail residents, $p<0.001)$ and those with dementia (38.6\% v. $21.6 \%$ among those without dementia, $p<0.001)$.

Interpretation: Within Ontario long-term care, trends suggest a shift toward increased use of hydromorphone but reduced prevalence of use of other opioid agents and potentially inappropriate opioid prescribing. Further investigation is needed on the impact of these trends on resident outcomes.



rescribers of opioid medications in long-term care settings face difficulties balancing appropriate pain management with the potential risks of these therapies in vulnerable older adults. Pain is highly prevalent among long-term care residents, ${ }^{1,2}$ although reliable pain assessment in this population is clinically challenging, particularly in those with dementia, who may have trouble expressing their pain management needs. ${ }^{3}$ Although undertreatment of pain is an important concern, ${ }^{4,5}$ the use of opioids in older adults is also associated with side effects and adverse events. ${ }^{6}$ Pharmacokinetic changes, such as agerelated declines in renal function and drug metabolism, place older adults at increased risk for sedation or opioid overdose. ${ }^{6}$ They are also more vulnerable to events such as falls ${ }^{7}$ and respiratory depression. ${ }^{8}$ Furthermore, polypharmacy is common in the long-term care population, which increases the risk of exposure to clinically significant drug interactions. These exposures include the concurrent use of opioids with benzodiazepines, which is associated with an elevated risk of overdose and death. ${ }^{9,10}$
In response to wider concerns around opioid use in the community, there have been a number of initiatives over the past decade focused on improving pain assessment and treatment, and on providing guidelines for appropriate and safer opioid prescribing. ${ }^{11-14}$ Recent Canadian guidelines for the management of chronic noncancer pain recommend avoiding escalation of daily dosages greater than $90 \mathrm{mg}$ of morphine equivalents (MME) and avoiding coprescribing opioids with benzodiazepines. ${ }^{13}$ The Ontario Narcotics Safety and Awareness Act, 2010 has led to increased surveillance of prescription opioids by introducing a provincial prescription-monitoring program for community prescribers. ${ }^{15}$ To date, Canadian

\section{Competing interests: None declared.}

This article has been peer reviewed.

Correspondence to: Colleen Maxwell, colleen.maxwell@uwaterloo.ca CMAJ Open 2019. DOI:10.9778/cmajo.20190052 
guidelines have not directly addressed the unique and clinically challenging issues surrounding opioid prescribing in long-term care, and empirical data regarding prescribing patterns in this setting are lacking. To address the sparseness of data in this area, we aimed to examine trends over time in the prescribing of opioids for long-term care residents in Ontario and variations by drug type, dosage and coprescription with benzodiazepines, and across resident subgroups.

\section{Methods}

\section{Study design, setting and data sources}

We conducted a population-based, repeated cross-sectional study of opioid use among long-term care residents in Ontario between Apr. 1, 2009, and Mar. 31, 2017. We used clinical and health administrative databases, including the Canadian Institute for Health Information Continuing Care Reporting System, the Ontario Drug Benefit Program database and the Registered Persons Database (see Supplementary Table S1, Appendix 1, available at www.cmajopen.ca/ content/7/3/E582/supp1/DC1, for a description of the databases). The databases were linked using unique encoded identifiers and analyzed at ICES. These databases have been used extensively to study medication use in the long-term care setting. ${ }^{16-19}$ In Ontario, the majority of the cost of long-term care is covered by the publicly funded provincial health care system. In addition, all residents have universal access to prescription medications, physician services and hospital care.

\section{Study population}

The Continuing Care Reporting System includes clinical assessment data for all long-term care residents, collected by means of the Resident Assessment Instrument Minimum Data Set version 2.0 (RAI-MDS 2.0) tool, a validated instrument. ${ }^{20}$ This tool provides a standardized and comprehensive assessment of residents' health and functional status, disease diagnoses and care needs. Mandatory full assessments are completed within 14 days of long-term care admission, annually and following any major change in health status (i.e., a change that is not self-limiting, affects more than 1 clinical area, and requires review or revision of the care plan). ${ }^{21}$ We identified all full clinical assessments with the RAI-MDS 2.0 during our study period among residents aged 66 years or more (to permit a 1-year look back for health care system access). As the use of opioids in palliative care and cancer pain are clearly indicated, our study focused on long-term care residents without cancer and those not receiving palliative care. Assessments were grouped into study years to align with provincial datareporting cycles, and we selected 1 assessment per resident for each year, giving preference to the earliest assessment (Figure 1).

\section{Medication use}

We used the Ontario Drug Benefit program database to ascertain all opioid and benzodiazepine drug claims whereby a course of therapy (estimated through the date dispensed plus days supplied) overlapped or included the RAI-MDS 2.0 assessment date. An assessment could have had multiple opioid claims meeting this definition. A list of all opioid medications included can be found in Supplementary Table S2, Appendix 1. We calculated the daily dosage of each opioid at the assessment date by multiplying the quantity of pills dispensed by the medication strength and dividing by the prescription duration in days. We derived the combined total daily dosage in MME using established conversion ratios (Supplementary Table S3, Appendix 1). ${ }^{22}$

Measures captured at each assessment date included the proportion of residents prescribed any opioid and the proportion who received specific opioid agents (codeine, hydromorphone, morphine, fentanyl and oxycodone), different formulations (long-acting and short-acting), a total daily dosage greater than $90 \mathrm{MME}$ and opioids coprescribed with benzodiazepines.

\section{Resident characteristics}

We determined age and sex at the assessment date using the Registered Persons Database. We used the RAI-MDS 2.0 data to identify assessments with a concurrent diagnosis of Alzheimer disease or other dementia, and liver disease or renal failure. ${ }^{23} \mathrm{We}$ also used assessment items from the RAI-MDS 2.0 to compute a validated measure of resident frailty, ${ }^{24,25}$ which included 72 deficits covering multiple domains of health (disease diagnoses, functional status, psychosocial well-being, cognition and communication). In accordance with previous work, ${ }^{24-26}$ we defined residents with more than $30 \%$ of potential deficits as frail. We used a measure of pain frequency in the RAI-MDS 2.0 to identify residents who experienced daily pain, less than daily pain or no pain in the 7 days before assessment. Finally, we used the RAI-MDS 2.0 to distinguish full assessments performed on entry to long-term care versus ongoing full assessments (occurring annually or after major health status changes) thereafter.

\section{Statistical analysis}

To summarize any changes that occurred over the 8-year study period, we compared the patterns of each opioid dispensing measure between the first $(2009 / 10)$ and last (2016/17) study year using log-binomial regression models to calculate the percent change. Adjusted models included age, sex, dementia diagnosis, frailty, diagnosis of liver disease or renal failure, and long-term care assessment type to control for any changes in the long-term care population across the study period. We did not include pain frequency in the adjusted models as pain may have been modified by opioid use. Because some residents may have been included in multiple study years, we used generalized estimating equations to account for the correlated nature of the data. ${ }^{27}$ For the annual measure of the proportion of residents receiving any opioid at the assessment date, we stratified the above analyses by age (categorized using the median cut-point $[\leq 85 \mathrm{yr}$ v. $>85 \mathrm{yr}]$ ), sex, dementia diagnosis, frailty, diagnosis of liver disease or renal failure, pain frequency at assessment (any pain v. no pain) and long-term care assessment type (entry v. ongoing assessment), and ran interaction tests to assess for any effect 


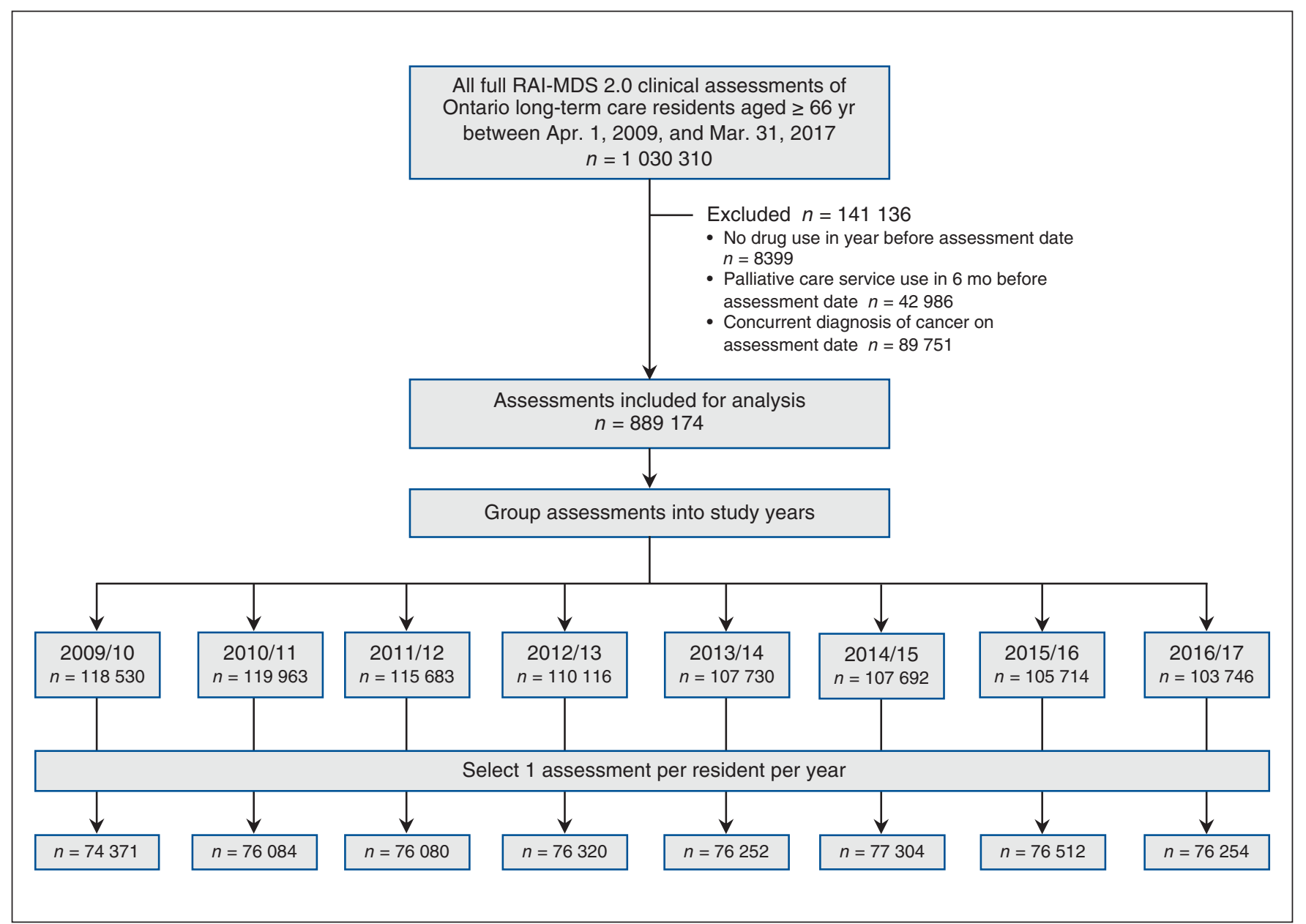

Figure 1: Flow diagram showing selection of study population. Note: RAI-MDS $2.0=$ Resident Assessment Instrument Minimum Data Set version 2.0 tool.

modification. We examined the significance of interaction terms with Wald tests. We conducted analyses using SAS version 9.4 (SAS Institute Inc.). All statistical tests were 2-tailed, and we defined $p<0.05$ as the level of statistical significance.

\section{Ethics approval}

The use of data in this study was authorized under section 45 of Ontario's Personal Health Information Protection Act, which does not require review by a research ethics board.

\section{Results}

Our study population comprised an average of 76147 longterm care residents per study year (Figure 1). The proportions of residents aged more than 85 years, with a diagnosis of dementia and defined as frail increased over the study period (Table 1).

\section{Trends in opioid prescribing}

The prevalence of any opioid prescription in long-term care increased by $23.8 \%$ over the study period, from $15.8 \%$ in $2009 / 10$ to $19.6 \%$ in $2016 / 17(p<0.001)$ (Figure 2, Table 2).
After adjustment for age, sex, frailty status, dementia diagnosis, diagnosis of liver disease or renal failure, and long-term care assessment type, this represented an increase of $29.9 \%$ in opioid prevalence during the study period. After adjustment, the use of most opioid agents decreased over the study period, including a $26.1 \%$ reduction in codeine prescribing, a $40.0 \%$ reduction in fentanyl prescribing and a $37.0 \%$ reduction in oxycodone prescribing. However, there was a coinciding increase of $233.2 \%$ (from $3.7 \%$ in $2009 / 10$ to $11.8 \%$ in 2016/17) in hydromorphone prescribing. Although the use of both opioid formulations increased significantly $(p<0.001)$ the increase was larger for short-acting formulations than for long-acting formulations (41.8\% v. $12.6 \%)$.

\section{Trends in safer opioid prescribing}

The overall adjusted use of high-dose opioids (total daily dosage > $90 \mathrm{MME}$ ) decreased by $17.7 \%$, from a prevalence in all residents of $4.8 \%$ in $2009 / 10$ to $3.6 \%$ in $2016 / 17$ ( $p<0.001$ ) (Table 2). In $2016 / 17,18.3 \%$ of opioid users had a total daily dosage greater than 90 MME (v. 30.2\% in 2009/10), and $70.5 \%$ had a total daily dosage less than $50 \mathrm{MME}$ (v. $60.3 \%$ in 2009/10). 


\begin{tabular}{|c|c|c|c|c|c|c|c|c|}
\hline \multirow[b]{2}{*}{ Characteristic } & \multicolumn{8}{|c|}{ Year; no. $(\%)$ of residents } \\
\hline & $\begin{array}{c}2009 / 10 \\
n=74371\end{array}$ & $\begin{array}{c}2010 / 11 \\
n=76084\end{array}$ & $\begin{array}{c}2011 / 12 \\
n=76080\end{array}$ & $\begin{array}{c}2012 / 13 \\
n=76320\end{array}$ & $\begin{array}{c}2013 / 14 \\
n=76252\end{array}$ & $\begin{array}{c}2014 / 15 \\
n=77304\end{array}$ & $\begin{array}{c}2015 / 16 \\
n=76512\end{array}$ & $\begin{array}{c}2016 / 17 \\
n=76254\end{array}$ \\
\hline \multicolumn{9}{|l|}{ Age, yr } \\
\hline$\leq 85$ & $38276(51.5)$ & $38263(50.3)$ & $37754(49.6)$ & $37095(48.6)$ & $36543(47.9)$ & $36610(47.4)$ & $36034(47.1)$ & $35409(46.4)$ \\
\hline$>85$ & $36095(48.5)$ & 37821 (49.7) & $38326(50.4)$ & $39225(51.4)$ & 39709 (52.1) & 40694 (52.6) & 40478 (52.9) & $40845(53.6)$ \\
\hline \multicolumn{9}{|l|}{ Sex } \\
\hline Female & $53994(72.6)$ & $54974(72.3)$ & $54785(72.0)$ & 54657 (71.6) & $54407(71.4)$ & 54887 (71.0) & $54153(70.8)$ & $53838(70.6)$ \\
\hline Male & $20377(27.4)$ & $21110(27.7)$ & $21295(28.0)$ & $21663(28.4)$ & $21845(28.6)$ & 22417 (29.0) & 22359 (29.2) & $22416(29.4)$ \\
\hline Dementia & $42856(57.6)$ & $45979(60.4)$ & $47433(62.3)$ & $48718(63.8)$ & $49087(64.4)$ & $50062(64.8)$ & $50205(65.6)$ & $50339(66.0)$ \\
\hline Frail & 37847 (50.9) & $39434(51.8)$ & 40247 (52.9) & $41985(55.0)$ & $42746(56.1)$ & $43770(56.6)$ & $43491(56.8)$ & $43849(57.5)$ \\
\hline $\begin{array}{l}\text { Liver disease or } \\
\text { renal failure }\end{array}$ & $6368(8.6)$ & $7237(9.5)$ & $7734(10.2)$ & $8126(10.6)$ & $8189(10.7)$ & $8436(10.9)$ & $8387(11.0)$ & 8511 (11.2) \\
\hline \multicolumn{9}{|l|}{ Pain frequency } \\
\hline No pain & $43151(58.0)$ & $44803(58.9)$ & $46210(60.7)$ & $48069(63.0)$ & $48954(64.2)$ & $50770(65.7)$ & $51418(67.2)$ & $52485(68.8)$ \\
\hline Any pain & $31220(42.0)$ & $31281(41.1)$ & 29870 (39.3) & $28251(37.0)$ & $27298(35.8)$ & $26534(34.3)$ & $25094(32.8)$ & 23769 (31.2) \\
\hline \multicolumn{9}{|l|}{$\begin{array}{l}\text { Long-term care } \\
\text { assessment type }\end{array}$} \\
\hline Entry & 17041 (22.9) & 21723 (28.6) & 21741 (28.6) & 21325 (27.9) & $22148(29.0)$ & $23480(30.4)$ & 22556 (29.5) & 22359 (29.3) \\
\hline Ongoing & 57330 (77.1) & $54361(71.4)$ & 54339 (71.4) & 54995 (72.1) & $54104(71.0)$ & 53824 (69.6) & $53956(70.5)$ & $53895(70.7)$ \\
\hline
\end{tabular}

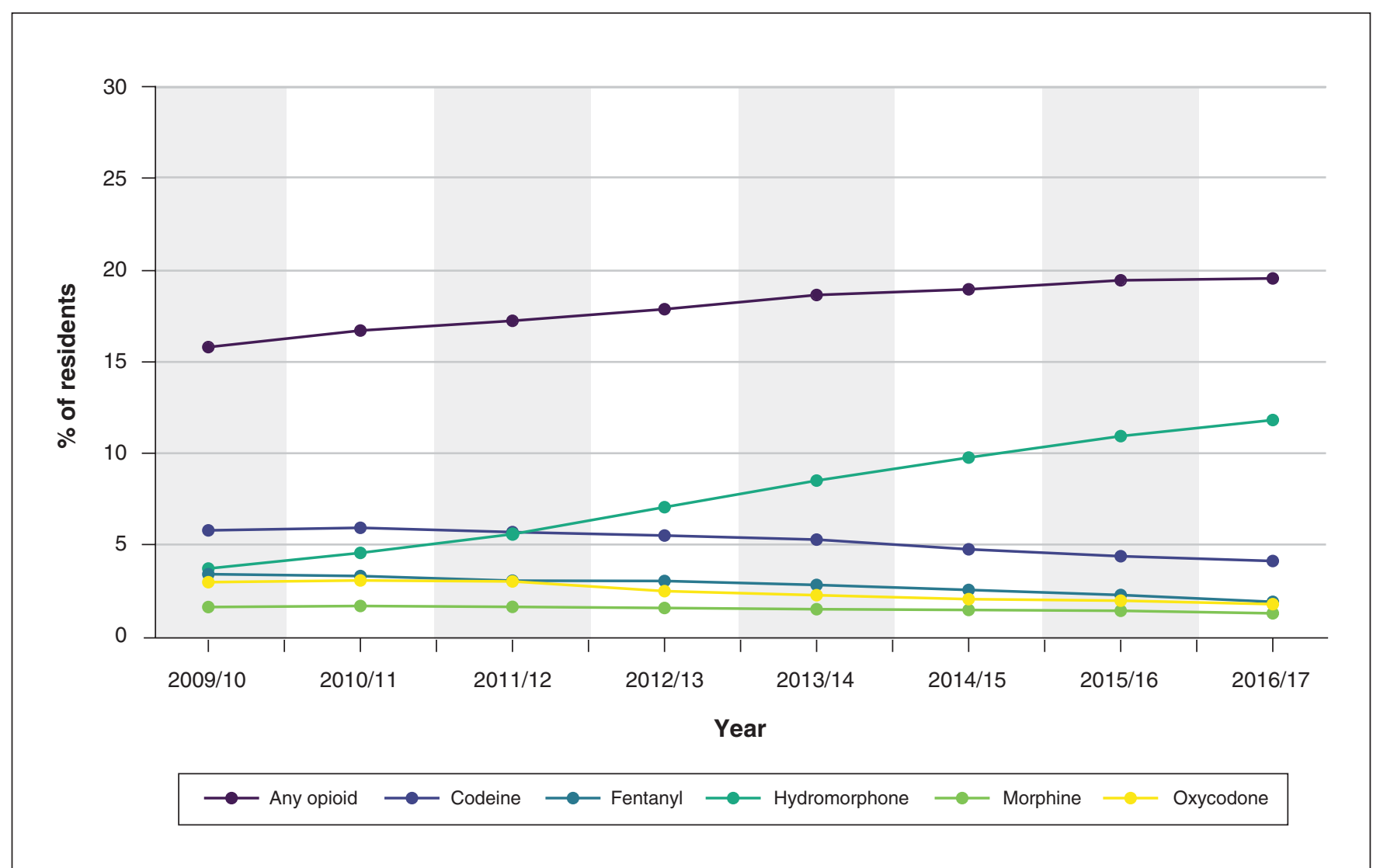

Figure 2: Proportion of Ontario long-term care residents who received any opioid and specific opioid agents in each study year, $2009 / 10$ to $2016 / 17$. 


\begin{tabular}{|c|c|c|c|c|c|c|}
\hline \multirow{2}{*}{$\begin{array}{l}\text { Opioid prescription on } \\
\text { assessment date }\end{array}$} & \multicolumn{2}{|c|}{$\%$ of residents } & \multicolumn{2}{|c|}{ Unadjusted results } & \multicolumn{2}{|c|}{ Adjusted results* } \\
\hline & $2009 / 10$ & $2016 / 17$ & $\%$ change & $p$ value & $\%$ change & $p$ value \\
\hline Any opioid & 15.8 & 19.6 & 23.8 & $<0.001$ & 29.9 & $<0.001$ \\
\hline \multicolumn{7}{|l|}{ Opioid agent } \\
\hline Codeine & 5.8 & 4.1 & -29.1 & $<0.001$ & -26.1 & $<0.001$ \\
\hline Hydromorphone & 3.7 & 11.8 & 220.8 & $<0.001$ & 233.2 & $<0.001$ \\
\hline Morphine & 1.6 & 1.2 & -21.9 & $<0.001$ & -16.5 & $<0.001$ \\
\hline Fentanyl & 3.4 & 1.9 & -44.9 & $<0.001$ & -40.0 & $<0.001$ \\
\hline Oxycodone & 2.9 & 1.7 & -41.0 & $<0.001$ & -37.0 & $<0.001$ \\
\hline \multicolumn{7}{|l|}{ Opioid formulation } \\
\hline Long-acting & 7.1 & 7.3 & 3.4 & 0.06 & 12.6 & $<0.001$ \\
\hline Short-acting & 10.7 & 14.6 & 37.2 & $<0.001$ & 41.8 & $<0.001$ \\
\hline $\begin{array}{l}\text { Opioid dosage }>90 \mathrm{mg} \text { of } \\
\text { morphine equivalents }\end{array}$ & 4.8 & 3.6 & -25.3 & $<0.001$ & -17.7 & $<0.001$ \\
\hline $\begin{array}{l}\text { Opioids coprescribed with } \\
\text { benzodiazepines }\end{array}$ & 4.8 & 3.4 & -29.8 & $<0.001$ & -23.8 & $<0.001$ \\
\hline
\end{tabular}

After adjustment, the proportion of all residents coprescribed opioids and benzodiazepines decreased by $23.8 \%$ over the study period, from $4.8 \%$ in $2009 / 10$ to $3.4 \%$ in $2016 / 17$ $(p<0.001)$. Among residents who were prevalent opioid users, this represented a reduction of $43.3 \%$ in the proportion also prescribed a benzodiazepine $(30.6 \%$ in $2009 / 10$ v. $17.4 \%$ in 2016/17).

\section{Trends in opioid prescribing by resident characteristics}

After adjustment, the percent increase in opioid prevalence over the study period was significantly greater for residents aged more than 85 years (v. those $\leq 85 \mathrm{yr} ; p=0.004$ for interaction), residents with dementia (v. residents without dementia; $p<0.001$ for interaction), frail residents (v. nonfrail residents; $p<0.001$ for interaction) and residents assessed as having no pain in the previous 7 days (v. residents assessed as having pain in this time period; $p<0.001$ for interaction) (Table 3). Although there was an increase of $38.6 \%$ in opioid prevalence among residents with dementia over time, opioid prescribing remained lower among those with dementia than among those without dementia (16.3\% v. $26.0 \%$ in 2016/17) (Figure 3, A). Opioid prevalence was higher among frail residents than among nonfrail residents and increased by $37.6 \%$ in the former group over the study period. Therefore, the gap in opioid prevalence between frail and nonfrail residents widened over time (Figure 3, B). Over the study period, the prevalence of opioids decreased by $3.9 \%$ among residents newly entering long-term care, compared to a $41.5 \%$ increase among ongoing residents $(p<$ 0.001 for interaction) (Table 3).

\section{Interpretation}

Opioid prescribing patterns among Ontario long-term care residents changed significantly between 2009/10 and 2016/17, with the most notable changes being a shift toward the use of hydromorphone and an increase over time in the prevalence of opioid dispensations in older, frailer, more cognitively impaired residents, and in those assessed as having no recent pain. These changes remained significant even after adjustment for the changing demographic characteristics of longterm care residents over the study period. Overall, there was an increase in the prescribing of opioid therapy in long-term care, with a point prevalence of $19.6 \%$ of residents in 2016/17. This increase in opioid prevalence was not attributable to admission of opioid users from the community into long-term care facilities and is in line with recent point prevalence estimates of opioid use in long-term care in Finland $(22 \%)^{28}$ and Norway (23\%), ${ }^{29}$ as well as with estimates among community-dwelling older adults in Ontario (22\%). ${ }^{30}$

In keeping with guideline-recommended practices for safer prescribing, ${ }^{13}$ prescriptions exceeding dosage guidelines and the coprescribing of benzodiazepines with opioids decreased significantly over the study period. Another observed change over time was a decrease in the use of codeine. Guidelines caution against the use of codeine for several reasons, including the potential for reduced effectiveness owing to genetic polymorphisms or drug interactions in the CYP2D6 pathway. ${ }^{31}$ The observed increasing preference for hydromorphone and the decrease in oxycodone prescribing are also in keeping with trends across Ontario more broadly after drug reimbursement changes were put in place, in 2012, to address 


\begin{tabular}{|c|c|c|c|c|c|c|c|c|}
\hline \multirow[b]{2}{*}{ Characteristic } & \multicolumn{2}{|c|}{$\%$ of residents } & \multicolumn{3}{|c|}{ Unadjusted results } & \multicolumn{3}{|c|}{ Adjusted results* } \\
\hline & $2009 / 10$ & $2016 / 17$ & $\%$ change & $p$ value & $\begin{array}{c}p \text { value } \\
\text { (interaction) }\end{array}$ & $\%$ change & $p$ value & $\begin{array}{c}p \text { value } \\
\text { (interaction) }\end{array}$ \\
\hline Age, yr & & & & & 0.02 & & & 0.004 \\
\hline$\leq 85$ & 16.6 & 20.2 & 22.4 & $<0.001$ & & 26.9 & $<0.001$ & \\
\hline$>85$ & 15.1 & 19.1 & 26.2 & $<0.001$ & & 33.1 & $<0.001$ & \\
\hline Sex & & & & & 0.9 & & & 0.9 \\
\hline Female & 17.2 & 21.3 & 24.2 & $<0.001$ & & 29.9 & $<0.001$ & \\
\hline Male & 12.2 & 15.4 & 25.8 & $<0.001$ & & 29.6 & $<0.001$ & \\
\hline Dementia & & & & & $<0.001$ & & & $<0.001$ \\
\hline No & 21.3 & 26.0 & 21.8 & $<0.001$ & & 21.6 & $<0.001$ & \\
\hline Yes & 11.8 & 16.3 & 38.5 & $<0.001$ & & 38.6 & $<0.001$ & \\
\hline Frail resident & & & & & $<0.001$ & & & $<0.001$ \\
\hline No & 15.0 & 16.7 & 11.5 & $<0.001$ & & 18.8 & $<0.001$ & \\
\hline Yes & 16.6 & 21.7 & 30.6 & $<0.001$ & & 37.6 & $<0.001$ & \\
\hline $\begin{array}{l}\text { Liver disease or } \\
\text { renal failure }\end{array}$ & & & & & 0.9 & & & 0.9 \\
\hline No & 15.6 & 19.2 & 23.4 & $<0.001$ & & 30.2 & $<0.001$ & \\
\hline Yes & 18.6 & 22.6 & 21.5 & $<0.001$ & & 27.7 & $<0.001$ & \\
\hline Pain frequency & & & & & $<0.001$ & & & $<0.001$ \\
\hline No pain & 6.9 & 12.4 & 80.0 & $<0.001$ & & 86.3 & $<0.001$ & \\
\hline Any pain & 28.1 & 35.3 & 25.6 & $<0.001$ & & 31.4 & $<0.001$ & \\
\hline $\begin{array}{l}\text { Long-term care } \\
\text { assessment type }\end{array}$ & & & & & $<0.001$ & & & $<0.001$ \\
\hline Entry & 16.6 & 15.4 & -7.3 & 0.001 & & -3.9 & 0.09 & \\
\hline Ongoing & 15.6 & 21.3 & 36.8 & $<0.001$ & & 41.5 & $<0.001$ & \\
\hline
\end{tabular}

the misuse of controlled-release oxycodone. ${ }^{22}$ The preference for hydromorphone may reflect its enhanced tolerability in those with renal impairment and potential to be prescribed in smaller dosages to mitigate side effects. At present, it is difficult to estimate the impact of policy changes designed to address the wider crisis of nonmedical opioid use and opioidrelated adverse events in the community on opioid prescribing in long-term care. However, it is important to note that concerns regarding opioid misuse may be less relevant in the long-term care setting, where medication administration is medically supervised, than in the community.

As observed in the current study and elsewhere, ${ }^{19,25}$ a majority of long-term care residents in Ontario have cognitive impairment, and there is a lack of evidence-based guidance for appropriate pain management in this population. ${ }^{32}$ Our findings are consistent with those of previous studies showing a gap in opioid prescribing between long-term care residents with and without dementia. ${ }^{33,34}$ Challenges in pain management in people with dementia arise out of changes in pain processing, perception and communication in dementia, and difficulties in assessing pain by observation, with misinterpretation of pain-related behaviours. ${ }^{33}$ For example, poorly managed pain may manifest as agitation or depression. ${ }^{35}$ There is evidence of benefit of the empiric stepwise treatment of pain in long-term care residents with dementia and agitation, starting with acetaminophen and proceeding to low-dose opioids. ${ }^{35}$ However, a recent clinical trial showed poor tolerability and lack of efficacy of buprenorphine for the treatment of depression in people with dementia. ${ }^{36,37}$

Although Canadian guidelines address the issue of age in opioid prescribing, they do not specifically address frailty as a prescribing consideration. ${ }^{13}$ Frail older adults are at increased risk for adverse events such as falls, fractures, delirium and cognitive impairment, ${ }^{24,25,38}$ but these risks need to be balanced with appropriate pain management. There is a paucity of evidence to guide the safe and effective prescribing of opioid therapy for pain in frail older adults. There remains a difficult balance between advocating for caution in the use and 


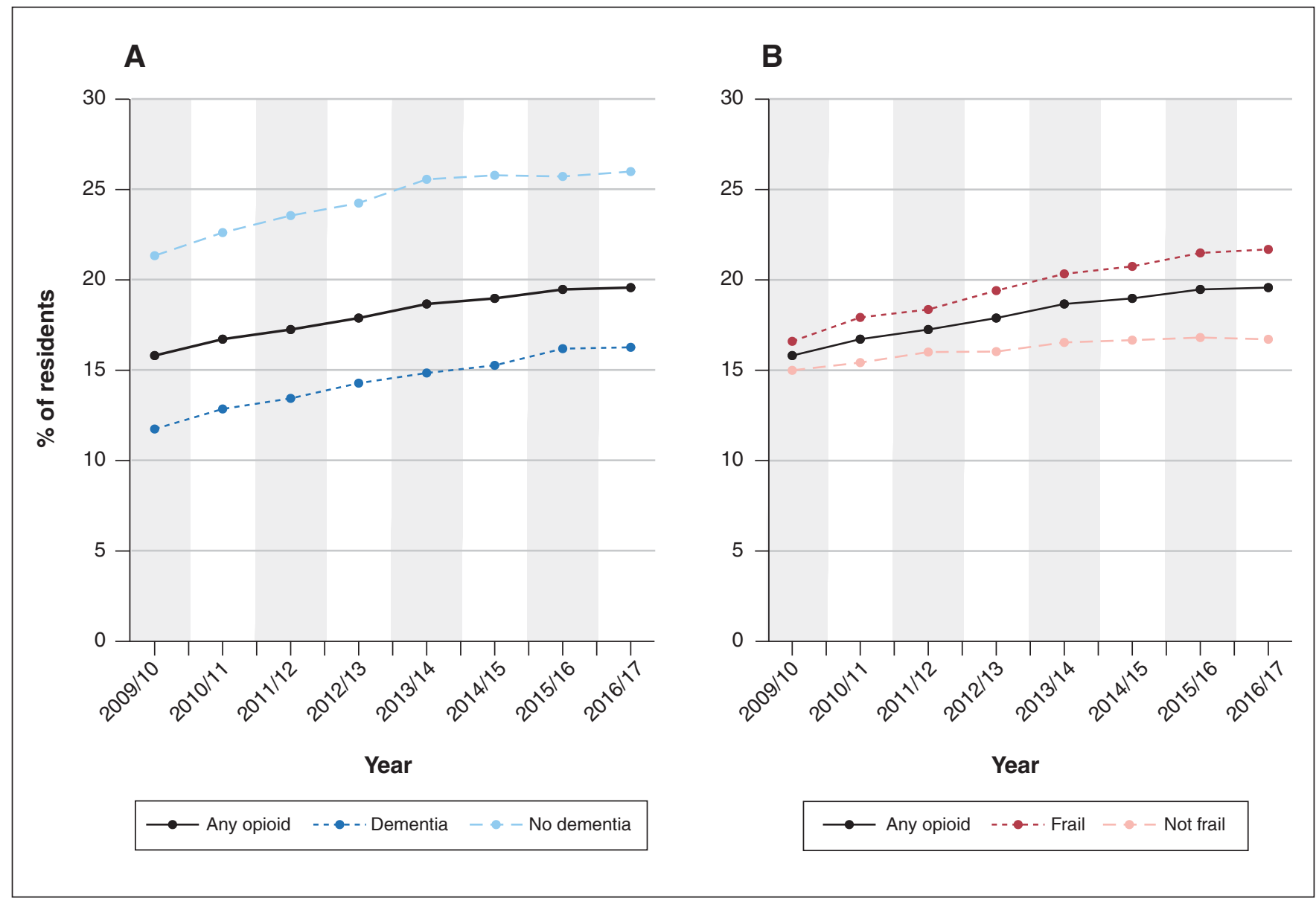

Figure 3: Proportion of Ontario long-term care residents who received any opioid in each study year, 2009/10 to 2016/17, stratified by dementia diagnosis $(A)$ and frailty $(B)$.

dosing of these therapies, and advocating for appropriate pain management. From our results, we are unable to determine whether the higher rates of prescribing among frail long-term care residents is related to the degree of comorbidity and medical complexity of this population or is an indicator of potentially inappropriate prescribing.

\section{Limitations}

In our analysis, we were unable to examine trends in possible under- or overtreatment of pain given the clinical and methodological challenges of measuring pain in the long-term care setting ${ }^{3,39,40}$ and without assessing any alternative nonopioid drug and nondrug pain-management strategies that may be available to long-term care residents. Data on the indication for opioid use were also not available. These factors, and the fact that pain is modified by opiate use, also contributed to difficulty in the interpretation of the painstratified analysis. Another limitation of this study is that there are a small number of opioid drugs and formulations that are not covered by the Ontario Drug Benefit program, namely buprenorphine and tramadol. From clinical experience, we know that these are rarely prescribed, as the uninsured drug costs are prohibitive to families, and their use is unlikely to have affected our results.

\section{Conclusion}

Although the prevalence of opioid prescribing increased in long-term care in Ontario between 2009/10 and 2016/17, with a large shift toward using hydromorphone, the declining use of high-dose opioids and benzodiazepine coprescribing is in line with Canadian guidelines for older adults. There remains an opportunity to address the prescribing gap between those with and without dementia and to better understand the appropriateness of treatment patterns among frail residents. Future studies should examine the impact of increased opioid prescribing on pain-related outcomes and on adverse events in the long-term care population.

\section{References}

1. Won AB, Lapane KL, Vallow S, et al. Persistent nonmalignant pain and analgesic prescribing patterns in elderly nursing home residents. 7 Am Geriatr Soc 2004;52:867-74.

2. Lapane KL, Quilliam BJ, Chow W, et al. The association between pain and measures of well-being among nursing home residents. 7 Am Med Dir Assoc 2012;13:344-9.

3. Barry HE, Parsons C, Passmore AP, et al. Pain in care home residents with dementia: an exploration of frequency, prescribing and relatives' perspectives. Int 7 Geriatr Psychiatry 2015;30:55-63.

4. Fain KM, Alexander GC, Dore DD, et al. Frequency and predictors of analgesic prescribing in U.S. nursing home residents with persistent pain. 7 Am Geriatr Soc 2017;65:286-93.

5. Griffioen C, Husebo BS, Flo E, et al. Opioid prescription use in nursing home residents with advanced dementia. Pain Med 2019;20:50-7. 
6. McLachlan AJ, Bath S, Naganathan V, et al. Clinical pharmacology of analgesic medicines in older people: impact of frailty and cognitive impairment. $\mathrm{Br} 7$ Clin Pharmacol 2011;71:351-64.

7. Daoust R, Paquet J, Moore L, et al. Recent opioid use and fall-related injury among older patients with trauma. CMA7 2018;190:E500-6.

8. Cepeda MS, Farrar JT, Baumgarten M, et al. Side effects of opioids during short-term administration: effect of age, gender, and race. Clin Pharmacol Ther 2003;74:102-12.

9. Sun EC, Dixit A, Humphreys K, et al. Association between concurrent use of prescription opioids and benzodiazepines and overdose: retrospective analysis. BM7 2017;356:1760.

10. Jann M, Kennedy WK, Lopez G. Benzodiazepines: a major component in unintentional prescription drug overdoses with opioid analgesics. 7 Pharm Pract 2014;27:5-16.

11. Assessment and management of pain. 3rd ed. Toronto: Registered Nurses' Association of Ontario; 2013.

12. Hadjistavropoulos T, Fitzgerald TD, Marchildon GP. Practice guidelines for assessing pain in older persons with dementia residing in long-term care facilities. Physiother Can 2010;62:104-13.

13. Kahan M, Wilson L, Mailis-Gagnon A, et al. Canadian guideline for safe and effective use of opioids for chronic noncancer pain: clinical summary for family physicians. Part 2: special populations. Can Fam Physician 2011;57:1269-76.

14. Dowell D, Haegerich TM, Chou R. CDC guideline for prescribing opioids for chronic pain [published erratum in: MMWR Recomm Rep 2016;65:295]. MMWR Recomm Rep 2016;65:1-49.

15. Gomes T, Juurlink D, Yao Z, et al. Impact of legislation and a prescription monitoring program on the prevalence of potentially inappropriate prescriptions for monitored drugs in Ontario: a time series analysis. CMA7 Open 2014; 2:E256-61.

16. Iaboni A, Bronskill SE, Reynolds KB, et al. Changing pattern of sedative use in older adults: a population-based cohort study. Drugs Aging 2016;33:523-33.

17. Campitelli MA, Maxwell CJ, Giannakeas V, et al. The variation of statin use among nursing home residents and physicians: a cross-sectional analysis. $7 \mathrm{Am}$ Geriatr Soc 2017;65:2044-51.

18. Daneman N, Campitelli MA, Giannakeas V, et al. Influences on the start, selection and duration of treatment with antibiotics in long-term care facilities. CMA7 2017;189:E851-60.

19. Maclagan LC, Bronskill SE, Guan J, et al. Predictors of cholinesterase discontinuation during the first year after nursing home admission. $7 \mathrm{Am} \mathrm{Med} \mathrm{Dir}$ Assoc 2018;19:959-66.e4.

20. Hirdes JP, Poss JW, Caldarelli H, et al. An evaluation of data quality in Canada's Continuing Care Reporting System (CCRS): secondary analyses of Ontario data submitted between 1996 and 2011. BMC Med Inform Decis Mak 2013;13:27.

21. Resident Assessment Instrument (RAI) MDS 2.0 user's manual, Canadian version. Ottawa: Canadian Institute for Health Information; 2012

22. Gomes T, Mastorakos A, Paterson JM, et al. Changes in the dispensing of opioid medications in Canada following the introduction of a tamper-deterrent formulation of long-acting oxycodone: a time series analysis. CMA7 Open 2017; 5:E800-7.

23. Lix LM, Yan L, Blackburn D, et al. Validity of the RAI-MDS for ascertaining diabetes and comorbid conditions in long-term care facility residents. $B M C$ Health Serv Res 2014;14:17.

24. Campitelli MA, Bronskill SE, Hogan DB, et al. The prevalence and health consequences of frailty in a population-based older home care cohort: a comparison of different measures. BMC Geriatr 2016;16:133.

25. Maclagan LC, Maxwell CJ, Gandhi S, et al. Frailty and potentially inappropriate medication use at nursing home transition. 7 Am Geriatr Soc 2017;65:2205-12.

26. Hogan DB, Freiheit EA, Strain LA, et al. Comparing frailty measures in their ability to predict adverse outcome among older residents of assisted living. BMC Geriatr 2012;12:56.

27. Lipsitz SR, Kim K, Zhao L. Analysis of repeated categorical data using generalized estimating equations. Stat Med 1994;13:1149-63.

28. Pitkala KH, Juola AL, Hosia H, et al. Eight-year trends in the use of opioids, other analgesics, and psychotropic medications among institutionalized older people in Finland. 7 Am Med Dir Assoc 2015;16:973-8.

29. Sandvik R, Selbaek G, Kirkevold O, et al. Analgesic prescribing patterns in Norwegian nursing homes from 2000 to 2011: trend analyses of four data samples. Age Ageing 2016;45:54-60.

30. Gomes T, Pasricha S, Martins D, et al. Bebind the prescriptions: a snapshot of opioid use across all Ontarians. Toronto: Ontario Drug Policy Research Network; 2017.

31. Owusu Obeng A, Hamadeh I, Smith M. Review of opioid pharmacogenetics and considerations for pain management. Pharmacotherapy 2017;37:1105-21.

32. Corbett A, Nunez KM, Smeaton E, et al. The landscape of pain management in people with dementia living in care homes: a mixed methods study. Int 7 Geriatr Psychiatry 2016;31:1354-70.
33. Achterberg WP, Pieper MJ, van Dalen-Kok AH, et al. Pain management in patients with dementia. Clin Interv Aging 2013;8:1471-82.

34. Tan EC, Jokanovic N, Koponen MP, et al. Prevalence of analgesic use and pain in people with and without dementia or cognitive impairment in aged care facilities: a systematic review and meta-analysis. Curr Clin Pharmacol 2015;10. 194-203.

35. Husebo BS, Ballard C, Sandvik R, et al. Efficacy of treating pain to reduce behavioural disturbances in residents of nursing homes with dementia: cluster randomised clinical trial. BMF 2011;343:d4065.

36. Erdal A, Flo E, Aarsland D, et al. Tolerability of buprenorphine transdermal system in nursing home patients with advanced dementia: a randomized, placebo-controlled trial (DEP. PAIN. DEM). Clin Interv Aging 2018;13: 935-46.

37. Erdal A, Flo E, Aarsland D, et al. Efficacy and safety of analgesic treatment for depression in people with advanced dementia: randomised, multicentre, double-blind, placebo-controlled trial (DEP. PAIN. DEM). Drugs Aging 2018; 35:545-58.

38. Fried LP, Tangen CM, Walston J, et al. Frailty in older adults: evidence for a phenotype. 7 Gerontol A Biol Sci Med Sci 2001;56:M146-56.

39. Wu N, Miller SC, Lapane K, et al. The quality of the quality indicator of pain derived from the minimum data set. Health Serv Res 2005;40:1197-216.

40. Cadogan MP, Schnelle JF, Yamamoto-Mitani N, et al. A minimum data set prevalence of pain quality indicator: Is it accurate and does it reflect differences in care processes? 7 Gerontol A Biol Sci Med Sci 2004;59:281-5.

Affiliations: Toronto Rehabilitation Institute (Iaboni), University Health Network; Department of Psychiatry (Iaboni), University of Toronto; ICES (Campitelli, Bronskill, Diong, Kumar, Maclagan, Gomes, Tadrous, Maxwell); Institute of Health Policy, Management and Evaluation (Bronskill, Gomes), University of Toronto; Sunnybrook Research Institute (Bronskill), Sunnybrook Health Sciences Centre; Women's College Research Institute (Bronskill, Tadrous), Women's College Hospital; Li Ka Shing Knowledge Institute (Gomes, Tadrous), St. Michael's Hospital; Leslie Dan Faculty of Pharmacy (Gomes, Tadrous), University of Toronto, Toronto, Ont.; Schools of Pharmacy and of Public Health and Health Systems (Maxwell), University of Waterloo, Waterloo, Ont.

Contributors: Andrea Iaboni, Michael Campitelli, Susan Bronskill and Colleen Maxwell conceived and designed the study. Michael Campitelli, Christina Diong and Matthew Kumar analyzed the data. Andrea Iaboni, Michael Campitelli, Susan Bronskill and Colleen Maxwell drafted the manuscript. All of the authors contributed to data interpretation, critically revised the manuscript for important intellectual content, approved the final version to be published and agreed to act as guarantors of the work.

Funding: This research was funded in part by the Canadian Institutes of Health Research through operating grant MOP-136854. This study was also supported by ICES, which is funded by an annual grant from the Ontario Ministry of Health and Long-Term Care.

Acknowledgement: The authors thank IMS Brogan for use of their Drug Information Database.

Disclaimer: The study sponsors provided the operating costs and infrastructure to support the research. No funding bodies had any role in the study design, data collection, analysis, decision to publish or preparation of the manuscript. This study was supported by ICES, which is funded by an annual grant from the Ontario Ministry of Health and Long-Term Care (MOHLTC). The opinions, results and conclusions reported in this article are those of the authors and are independent from the funding sources. No endorsement by ICES or the Ontario MOHLTC is intended or should be inferred. Parts of this material are based on data and information compiled and provided by the Canadian Institute for Health Information (CIHI). However, the analyses, conclusions, opinions and statements expressed herein are those of the authors and not necessarily those of CIHI.

Supplemental information: For reviewer comments and the original submission of this manuscript, please see www.cmajopen.ca/content/7/3/ E582/suppl/DC1. Please contact the authors for any supplemental information related to the study such as the study protocol, analysis plan or analytic code. 